\title{
Clinical case management for patients with schizophrenia with high care needs
}

Authors: Laia Mas-Expósito ${ }^{1,2}$, Juan Antonio Amador-Campos ${ }^{2,3}$, Juana Gómez-Benito ${ }^{3,4}$, Lluís MauriMas $^{5}$, Lluís Lalucat-Jo ${ }^{1,6^{*}}$ for the Research Group on Severe Mental Disorder ${ }^{7}$

1. Department of Research, Centre d'Higiene Mental Les Corts, Barcelona, Spain.

2. Department of Personality, Assessment and Psychological Treatment, Faculty of Psychology, University of Barcelona, Barcelona, Spain.

3. Institute for Brain, Cognition and Behaviour, Barcelona, Spain. (IR3C), University of Barcelona, Barcelona, Spain.

4. Department of Methodology of the Behavioral Sciences, Faculty of Psychology, University of Barcelona, Barcelona, Spain.

5. Department of Research and Teaching, Fundació Hospital Sant Pere i Claver, Barcelona, Spain.

6. Research Commission, Fòrum d'Iniciatives Assistencials i de Gestió en Salut Mental a Catalunya.

7. The Working Group on Severe Mental Disorder is composed of the following members from Adult Mental Health Care Centres in Barcelona: Ma A. Argany, F. Asensio, M. Berruezo, C. Blecua, I. Bros, A. I. Cerrillo, A. del Cuerpo, A. Escudero, J. Farré, C. Fort, M. García, M. C. González, E. Leno, L. Mauri, I. Mitjà, M. Montoro, M. Nicolás, R. Ordoñez, C. Pinedo, M. Prats, M. J. Redin, M. T. Romero, F. Segarra, J. C. Valdearcos, I. Zafra, M. Zamora and A. Zúñiga.

*Corresponding author. Departament de Docència, Formació, Recerca i Publicacions, Centre d'Higiene Mental Les Corts, c/Numància 103-105 baixos, 08029, Barcelona, Spain. Tel.: +34 93 4198611. Fax: +34 93 4448968. E-mail address: 1luis.lalucat@chmcorts.com (L. Lalucat-Jo).

This study was supported by grant PI050789 from the Ministry of Health and Consumer Affairs of Spain, Carlos III Institute of Health, Health Research Fund, Madrid, Spain, and grant 2009SGR00822 from the Agency for Management of University and Research Grants, Government of Catalonia, Barcelona, Spain. 


\begin{abstract}
The aim of this study is to establish the effectiveness of a clinical case management (CM) programme compared to a standard treatment programme (STP) in patients with schizophrenia. Patients for the CM programme were consecutively selected among patients in the STP with schizophrenia who had poor functioning. Seventy-five patients were admitted to the CM programme and were matched to 75 patients in the STP. Patients were evaluated at baseline and at one year follow-up. At baseline, patients in the CM programme showed lower levels of clinical and psychosocial functioning and more care needs than patients in the STP. Both treatment programmes were effective in maintaining contact with services but the CM programme did not show advantages over the STP on outcomes. Differences between groups at baseline may be masking the effects of CM at one year follow-up. A longer follow-up may be required to evaluate the real CM practices effects.
\end{abstract}

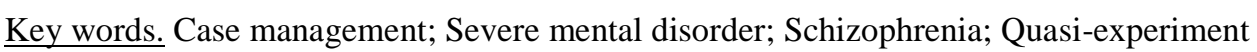




\section{Clinical case management for patients with schizophrenia with high care needs}

\section{Introduction}

Case Management (CM) is one of the main components of the services for persons with severe mental disorders (SMDs). Although CM was initially defined as a way of coordinating resources for a patient, nowadays, case manager activities are broader and usually include the direct provision of services (Mueser, Bond, Drake, and Resnick, 1998). CM is successful in community-based models (Marshall, Gray, Lockwood, and Green, 2000; Mueser et al., 1998; Van Os, 2009; Ziguras and Suart, 2000) in outcomes such as treatment compliance, hospital admissions, satisfaction and quality of life.

In Spain, where mental health care is community-based, CM has proven to be cost-effective in decreasing the burden of schizophrenia (Gutiérrez-Recacha, Chisholm, Haro Abad, Salvador-Carulla, and AyusoMateos, 2006) and use of services (Alonso Suárez et al., 2011). In Catalonia, a Spanish autonomous community, a new model of mental health care was developed during the transition to democracy. It led to a public mental health network integrated into the national health system, organised into health care sectors and based on Adult Mental Health Centres (AMHCs) and hospitals and community rehabilitation centres. AMHCs consist of multidisciplinary teams (psychiatrists, psychologists, nurses and social workers) that offer outpatient and specialist care for mental disorders through programmes and interventions included in their care services during office hours. Since their establishment, AMHCs offer care to patients with SMDs through a Standard Treatment Program (STP) that includes: 1) general clinical and psychosocial assessments; and 2) medical interventions and follow-ups.

In 1997, the Health Department of Catalonia developed a specific type of CM programme for patients with SMDs that requires a higher level of care and other resources in addition to those in the STP. Its elements are those described by Ruggeri and Tansella (2008) and it meets the criteria of a clinical CM model by offering direct provision of care, and of a non-intensive CM programme since the caseload size is over 20 patients (Dieterich, Irving, Park, and Marshall, 2010). Table 1 shows a detailed description of the STP and the CM programme. All interventions in both programmes follow the Clinical Practice Guideline for Schizophrenia (Working group of the clinical practice guideline for schizophrenia and incipient psychotic disorder, 2009).

Insert here Table 1 
Studies on the effects of CM in Spain are scarce, have been conducted without control groups and are restricted to specific outcomes (Alonso Suárez et al., 2011; Gutíerrez-Recacha et al., 2006). This paper deals with these issues by establishing the effectiveness of a clinical CM programme versus a STP regarding clinical, psychosocial and service use variables.

\section{Methods}

A quasi-experimental study, pre-post, two groups, one quasi-control, was used.

\section{Participants}

The sample was composed of 150 patients (67.3\% males; 75 in the CM programme and 75 in the STP). Seventy percent of patients in both programmes had illness duration longer than 10 years, $66.7 \%$ of them had diagnosis of paranoid schizophrenia and their mean age was 41.47 years $(\mathrm{SD}=11.80)$. There were significant differences between the study groups in the type of housing they lived in. A lower percentage of patients in the CM programme reported to live in family-owned housing (See Table 2).

Insert here Table 2

Patients were recruited from December 2006 to January 2008 from 10 AMHCs in Barcelona (Catalonia, Spain). All patients had: 1) diagnosis of schizophrenia according to the International Classification of Diseases-10 or ICD-10 (World Health Organization [WHO], 1995), 2) illness duration greater than 2 years and 3) clinical stability. Patients were excluded if they had dementia, organic brain injury or mental retardation. Patients for the CM programme were consecutively selected among those in the STP visiting the AMHCs with a Global Assessment of Functioning or GAF total score $\leq 50$ (Endincott, 1976). Patients in the STP were selected from the AMHC databases through an intentional non-probabilistic sampling among all patients in the STP that could be matched with the patients selected for the CM programme regarding: age ( \pm 5 years), gender, illness length ( \pm 5 years) and symptoms by the Positive and Negative Syndrome Scale or PANSS (Kay, Friszbein, and Opler, 1987; PANSS total score, \pm 10 points) [PANSS total: $\mathrm{CM}=87.59, \mathrm{STP}=85.87, \mathrm{t}=0.851, \mathrm{p}=0.396$; PANSS positive: $\mathrm{CM}=17.60, \mathrm{STP}=17.08, \mathrm{t}=0.669$, $\mathrm{p}=0.504$; PANSS negative: $\mathrm{CM}=25.64, \mathrm{STP}=25.15, \mathrm{t}=0.537, \mathrm{p}=0.592$; PANSS general: $\mathrm{CM}=44.35$, $\mathrm{STP}=43.64, \mathrm{t}=0.560, \mathrm{p}=0.576]$.

\section{Instruments}

Patients were assessed at baseline and at one year follow-up with these instruments: 
The Schizophrenia Cost Evaluation Questionnaire (Haro et al., 1998). It records on the use of health care and social services.

The GAF (Endincott, 1976). This is a valid measure of psychological functioning in persons with SMD included in the fourth edition of the Diagnostic and Statistical Manual of Mental Disorders (American Psychiatric Association [APA], 1994).

The PANSS (Kay et al., 1987). It assesses symptom severity in persons with schizophrenia. Its validation into Spanish shows good psychometric properties (Peralta and Cuesta, 1994).

The Disability Assessment Schedule short version or DAS-s (Janca et al., 1996). It is a valid and reliable measure of functioning for mental disorders included in the ICD-10 (WHO, 1995) validated in persons with schizophrenia (Mas-Expósito, Amador-Campos, Gómez-Benito, and Lalucat-Jo, 2012a).

The Camberwell Assessment of Needs or CAN (Phelan, Slade, and Thornicroft, 1999). It measures the needs of people with mental illness and shows good psychometric properties in persons with schizophrenia (Rosales, Torres, Del Castillo, Jímenez, and Martínez, 2002).

The World Health Organization Quality of Life Scale Brief Version (WHO, 1993) or WHOQOL-BREF. It is an international, cross-culturally analogous quality of life (QoL) instrument that shows good psychometric properties in persons with schizophrenia (Mas-Expósito, Amador-Campos, Gómez-Benito, and Lalucat-Jo, 2011).

The modified DUKE-UNC Functional Social Support Questionnaire or FSSQ (Broadhead, Gelbach, Degruy, and Kaplan, 1988). It measures the strength of social networks. The Spanish version shows good psychometric properties in primary care patients (Bellón-Saameño, Delgado-Sánchez, de Dios-Luna del Castillo, and Lardelli-Claret, 1996) and in patients with schizophrenia (Mas-Expósito, Amador-Campos, Gómez-Benito, and Lalucat-Jo, 2012b).

\section{$\underline{\text { Procedure }}$}

Each AMHC provided both programmes. The AMHC teams performed patient assessments. For both programmes, the psychiatrists established the diagnosis, following the ICD-10 (WHO, 1995) research diagnosis criteria and considered self and caregiver reports, and assessed psychiatric symptoms. The rest of assessments were performed by the other members of the teams under the psychiatrist's supervision or by a community psychiatric nurse from the teams in the STP. The psychiatrist was responsible for setting up and supervising the assessment agenda and sending the score sheets to the psychologist who designed and analysed the database. 
To guarantee quality data, the psychiatrists participated in a schizophrenia diagnostic consensus workshop comprising two case studies. All researchers were trained in the instruments in a 4-hour session run by a psychologist. Systematic reviews of data coding and recording were made and patient information was compared with data from the AMHC responsible for each patient.

\section{$\underline{\text { Statistical analysis }}$}

Clinical and psychosocial outcomes and use of health services were analysed using the Statistical Package for the Social Sciences v. 19. Chi-square analysis and Student's t-tests for independent samples were used for categorical and continuous data, respectively. Mann-Whitney U tests were applied for continuous data to compare independent samples with fewer than 30 patients.

\section{Ethical considerations}

The study was approved by the Ethics Committee of the Catalan Union of Hospitals and carried out in accordance with the ethical standards of the 1964 Declaration of Helsinki. The procedures were described to each patient who then provided informed consent.

\section{Results}

A total of 69 patients $(92 \%)$ in the CM programme were successfully followed up. Four individuals (out of 6) had no contact with services, 1 refused to participate and 1 committed suicide. Regarding the STP, 69 patients (92\%) were successfully followed up. Six patients had no contact with services. No significant differences between study groups were observed regarding treatment attrition $\left(\chi^{2}(1)=0.000 ; p>0.05\right)$.

Table 3 shows the differences between the CM programme group and the STP group in clinical and psychosocial variables at baseline and at one year follow-up. At baseline, no significant differences were found between the CM programme and the STP groups in disability, subjective QoL regarding psychological health, social relationships and environment, and perceived social support. However, there were significant differences between groups in patients' needs from the clinician's point of view, clinical and social functioning, subjective QoL regarding physical health and overall QoL (Table 3). Patients in the CM programme group showed more needs, lower clinical and social functioning, and lower subjective QoL regarding physical health and overall QoL compared to patients in the STP. At one year follow-up, there were intergroup differences in social functioning. Patients from the CM group showed poorer social functioning than patients in the STP

Insert here Table 3 
Table 4 shows the use of health services for the CM group and the STP group at baseline and at one year follow-up for categorical variables. At baseline, there were significant differences between the study groups in the proportion of patients that used acute units, overall inpatient hospital services, emergency services and social services. A greater proportion of patients from the CM group used those services. After one year follow-up, there were differences between groups in the proportion of patients who used overall outpatient psychiatric services, community social work services, social services and primary care nursing services. A greater proportion of patients from the CM group used outpatient psychiatric services, community social work services and social services, while a greater proportion of patients from the STP used primary care nursing services.

\section{Insert here Table 4}

Table 5 shows the use of health services for the CM group and the STP group at baseline and at one year follow-up for continuous variables. At baseline, there were significant differences between the study groups in outpatient hospital visits, overall outpatient psychiatric hospital visits, community psychiatric visits and community psychiatric nursing visits. Patients in the CM group had more visits to all those services. After one year follow-up, there were differences between the groups in community psychiatric nursing visits. The CM programme group showed higher number of visits to community psychiatric nursing services.

Insert here Table 5

\section{Discussion}

This paper aimed to establish the effectiveness of a CM programme versus a STP regarding clinical, psychosocial and service use variables.

Both programmes were effective in maintaining contact with services. Only eight per cent of patients in each programme lost contact with services, which concurs with Marshall et al. (2000) with regard to the efficacy of CM and points out favourable effects regarding the STP.

CM did not show any advantage over the STP on the clinical and psychosocial outcomes considered. Therefore, our results seem to coincide with those in a meta analyses conducted by Marshall et al. (2000) on the efficacy of CM versus standard care. Namely, the results of this meta analyses showed no benefit of CM over standard care on functioning, quality of life, needs, self-esteem, satisfaction and psychological well-being. Even so, a closer examination of our figures may be pointing out different 
conclusions. Throughout the study, it seems there was a tendency to clinical improvement in the CM group, which could be masked because of baseline differences between groups. When we look at needs means in Table 2, we realize that, at one-year follow-up, the CM group reduced its level of needs by about two points while the STP group kept the same baseline level. The same trend is observed on quality of life concerning physical health. As for the rest of variables (i.e. clinical and social functioning and overall quality of life) both treatment programmes seemed to improve but those improvements seemed greater for the CM group. When looking at the results in this way, our findings coincide with those in a meta-analyses on the effectiveness of clinical CM versus usual treatment in clinical functioning (Ziguras and Stuart, 2000) and in other reviews (Mueser et al., 1998). Our results coincide as well with those from other studies (Lichtenberg, Levinson, Sharshevsky, Feldman, and Lachman, 2008) that found improvements in subjective QoL but with a non-validated scale. We used the WHOQOL-BREF (WHO, 1993) which has good psychometric properties in persons with schizophrenia (Mas-Expósito et al., 2011b). To our knowledge, this is the first study conducted in Spain dealing with this relevant outcome (Van Esch, Den Oudsten, and De Vries, 2011). Our results also suggest that CM was associated with decreasing health care needs. Studies are needed to see whether our findings are replicated. It is important highlighting that needs are considered a key component for the recovery of this sample population (Werner, 2012). A longer follow-up period might be required to determine CM effects (Lichtenberg et al., 2008).

CM did not show any advantage over the STP on use of health care services but, even so, it is worth to make some considerations since, again, baseline differences could be masking CM effects. At one year follow-up, most of baseline between-group differences were not present anymore. If we look in detail at the results of Table 4, we realize that there was a reduction by half in the proportion of patients that used inpatient hospital services and emergency services in the CM group. Our results seem to contradict CM studies in other settings where CM is associated with increasing hospitalisation (Marshall et al., 2000; Ziguras and Stuart, 2000). Nevertheless, they concur with Spanish studies about the effectiveness of clinical CM (Alonso Suárez et al., 2011) that show a drop in the number of hospitalised patients which is similar to that observed in our study. Alonso Suárez et al. (2011) also showed a significant decrease in the number of patients visiting emergency rooms. To our knowledge, ours is the second study conducted regarding this outcome. One should also take into account that the STP group also reduced about the same the use of inpatient hospital services and emergency services. Even so, the reduction observed in the 
CM group seems enough to decrease differences with the STP at one-year follow-up. Considering that both groups had different levels of clinical stability at baseline, we would like to suggest a longer followup to evaluate $\mathrm{CM}$ effects at medium or long-term. At follow-up, the CM group still used more social services, which may be associated to their poorer social functioning at both assessment points and there were new differences regarding some health care services. A higher proportion of patients in the CM programme group used overall outpatient hospital services, while a higher proportion of patients in the STP group used primary care nursing services. One possible explanation might be that, after the followup, patients were ready to use less intensive services. At baseline, the CM group made more visits to outpatient hospital services, outpatient psychiatric hospital services, community psychiatric services and community psychiatric nursing services. At one year follow up, the CM programme group only showed more community psychiatric nursing visits. There was an increase of visits in the CM programme group not observed in the STP, which coincides with the metanalyses of Ziguras and Stuart (2000) that shows that clinical CM increases contact with services. The increase of such visits in the CM group might have turned into a decrease of outpatient psychiatric hospital service visits. Hospital service use was quite low, which contradicts the hypothesis that CM is effective where hospital bed use is high (Burns et al., 2007) but coincides with other Spanish studies (Alonso Suárez et al., 2011).

Although the aforementioned strengths when comparing our study with other Spanish studies, our results are limited to a one year follow-up. As suggested by some authors (Björkman and Hansson, 2007), certain outcomes regarding CM practices for persons with SMD do not appear in a short-term perspective (i.e. between 6 to 24 months). In addition, we did not used a randomised controlled design but a quasiexperimental design that is considered to be appropriate in clinical and ordinary settings, such as that in this study (Campbell and Stanley, 1966). Further research may consider new components in the CM programme such as an adjunct exercise programme, which has been considered feasible for coping with the high rates of morbidity and mortality in persons with schizophrenia (Sylvia et al., 2012). Other factors that further research may consider when evaluating CM effects is patient perceived criticism. It has been positively associated to higher levels of psychiatric symptoms (Guada, Hoe, Floyd, Barbour and Brekke, 2011).

In summary, the CM group did not show any advantage over the STP group on clinical and psychosocial outcomes and health care service use. The CM group showed lower levels of clinical and social 
functioning, and more care needs than the STP group at baseline, which could be masking the results. A longer follow-up is required before drawing conclusions about the effectiveness of those interventions.

\section{References}

Alonso Suárez, M., Bravo-Ortiz, M.F., Fernández-Liria, A., and González-Juárez, C. (2011). Effectiveness of Continuity-of-Care Programs to reduce time in hospital in persons with schizophrenia. Epidemiology and Psychiatric Sciences, 20, 65-72.

American Psychiatric Association. (1994). Diagnostic and Statistical Manual of Mental Disorders (4th ed.). Washington, DC: American Psychiatric Association.

Bellón-Saameño, J.A., Delgado-Sánchez, A., de Dios-Luna del Castillo, J., and Lardelli-Claret, P. (1966). Validez y fiabilidad del cuestionario de apoyo social funcional Duke-UNC-11. Atención Primaria, 18, 153-163.

Björkmann, T. and Hansson, L. (2007). Case management for individuals with a severe mental illness: a 6-year follow-up study. The International Journal of Social Psychiatry, 53, 12-22.

Broadhead, W.E., Gelbach, S.H., Degruy, F.V., and Kaplan, V.H. (1988). The Duke-UNC functional social support questionnaire: measurement of social support in family medicine patients. Medical Care, 26, 709-723.

Burns, T., Catty, J., Dash, M., Roberts, C., Lockwood. A., and Marshall, M. (2007). Use of intensive case management to reduce time in hospital in people with severe mental illness: a systematic review and meta-regression. British Medical Journal, 335, 1-7.

Campbell, D.T. and Stanley, J.C. (1966) Experimental and Quasi-Experimental Designs for Research. Chicago, IL: Rand McNally.

Dieterich, M., Irving, C.B., Park, B., and Marshall M. (2010). Intensive case management for severe mental illness. Cochrane Database of Systematic Reviews, 10, CD007906.

Endincott, J. (1976). The Global Assessment Scale: a procedure for measuring overall severity of psychiatric disturbance. Archives of General Psychiatry, 33, 766-771.

Guada, J., Hoe, M., Floyd, R., Barbour, J., and Brekke, J.S. (2011). The importance of consumer perceived criticism on clinical outcomes for outpatient African Americans with schizophrenia. Community Mental Health Journal, 47, 637-645. 
Gutiérrez-Recacha, P., Chisholm, D., Haro Abad, J.M., Salvador-Carulla, L., and Ayuso-Mateos, J.L. (2006). Cost-effectiveness of different clinical interventions for reducing the burden of schizophrenia in Spain. Acta Psychiatrica Scandinavica, 114, 29-38.

Haro, J.M., Salvador-Carulla, L., Cabases, J., Madoz, V., Vázquez-Barquero, J.L., and PSICOST group. (1998). Utilization of mental health services and costs of patients with schizophrenia in three areas of Spain. British Journal of Psychiatry, 173, 334-340.

Janca, A., Kastrup, M., Katschnig, H., López-Ibor, J.J., Mezzich, J.E., and Sartorius, N. (1996). The World Health Organization Short Disability Assessment Schedule (WHO DAS-S): a tool for the assessment of difficulties in selected areas of functioning of patients with mental disorders. Social Psychiatry and Psychiatric Epidemioloy, 31, 349-354.

Kay, R.S., Fiszbein, A., and Opler L. (1987). The Positive and Negative Syndrome Scale (PANSS) for schizophrenia. Schizophrenia Bulletin, 13, 261-276.

Lichtenberg, P., Levinson, D., Sharshevsky, Y., Feldman, D., and Lachman, M. (2008). Clinical case management of revolving door patients - a semi-randomized study. Acta Psychiatrica Scandinavica, 117, 449-54.

Marshall, M., Gray, A., Lockwood, A., and Green, R. (2000). Case management for people with severe mental disorders. Cochrane Database of Systematic Reviews, 2, CD000050.

Mas-Expósito, L., Amador-Campos, J.A., Gómez-Benito, J., and Lalucat-Jo, L. (2011). The World Health Organization Quality of Life Scale Brief Version: a validation study in patients with schizophrenia. Quality of Life Research, 20, 1079-1089.

Mas-Expósito, L., Amador-Campos, J.A., Gómez-Benito, J., and Lalucat-Jo, L. (2012a). The World Health Organization Short Disability Assessment Schedule (DAS-s): a validation study in patients with schizophrenia. Comprehensive Psychiatry, 53, 208-216.

Mas-Expósito, L., Amador-Campos, J.A., Gómez-Benito, J., and Lalucat-Jo, L. (2012b). Validation of the modified DUKE-UNC Functional Social Support Questionnaire in patients with schizophrenia. Social Psychiatry and Psychiatric Epidemiology, DOI 10.1007/s00127-012-0633-3.

Mueser, K.T., Bond, G.R., Drake, R.E., and Resnick, S.G. (1998). Models of community care for severe mental illness: a review of research on case management. Schizophrenia Bulletin, 24, 37-74. 
Peralta, V. and Cuesta, M.J. (1994). Validación de la escala de los síndromes positivo y negativo (PANSS) en una muestra de esquizofrénicos españoles. Actas Luso Españolas de Neurología, Psiquiatría y Ciencias Afines, 22, 171-177.

Phelan, M., Slade, M., and Thornicroft, G. (1999). The Camberwell Assessment of Need: The Validity and Reliability of an Instrument to Assess the Needs of People with Severe Mental Illness. British Journal of Psychiatry, 167, 589-595.

Rosales, C., Torres, F., Del Castillo, L., Jímenez. J., and Martínez, G. (2002). Evaluación de necesidades de personas con enfermedad esquizofrénica. Actas Españolas de Psiquiatría, 30, 99-104.

Ruggeri, M. and Tansella, M. (2008). Case management and assertive community treatment: are they really alternative approaches? Epidemiologia e Psichiatria Sociale, 17, 93-98.

Sylvia, L.G., Kopeski, L., Brown, C., Bolton, P., Laudate, C., Digangi, G.,.., Neuhaus, E.C. (2012). An Adjunct Exercise Program for Serious Mental Illness: Who Chooses to Participate and is it Feasible? Community Mental Health Journal, DOI 10.1007/s10597-012-9555-5.

Van Esch, L., Den Oudsten, B.L., and De Vries, J. (2012). The World Health Organization Quality of Life instrument-short form (WHOQOL-BREF) in women with breast problems. International Journal of Clinical and Health Psychology, 11, 5-22.

Van Os, J. (2009). Schizophrenia treatment: content versus delivery. Acta Psychiatrica Scandinavica, 119, 29-32.

Werner, S. (2012). Needs Assessment of Individuals with Serious Mental Illness: Can It Help in Promoting Recovery? Community Mental Health Journal, 48, 568-573.

Working Group of the Clinical Practice Guideline for Schizophrenia and Incipient Psychotic Disorder. (2009). Clinical Practice Guideline for Schizophrenia and Incipient Psychotic Disorder. Madrid: Quality Plan for the National Health System of the Ministry of Health and Consumer Affairs and Agency for Health Technology Assessment and Research.

World Health Organization. (1993). Measuring quality of life. The development of the World Health Organization Quality of Life Instrument (WHOQOL-100). Geneva: World Health Organization.

World Health Organization. (1995). The ICD-10 Classification of Mental and Behavioural Disorders. Geneva: World Health Organization.

Ziguras, S. and Stuart, G.W. (2000). A Meta-Analysis of the Effectiveness of Mental Health Case Management Over 20 Years. Psychiatric Services, 51, 1410-1421. 
Table 1. Intervention Programme Characterisation

Programme

ST

$\mathrm{CM}$

Clinician in Psychiatrist

Psychiatrist

charge

Case manager

Assessment

Global assessment:

- Medical aspects: symptoms, clinical functioning, treatment adherence and drug side effects.

- Psychosocial assessment: social functioning in general terms

Therapeutic

plan

Treatment Medical intervention :

- pharmacological treatment set up
Community mental health nurse

Systematic assessment:

- Medical assessment: symptoms, clinical functioning treatment adherence and drug side effects

- Psychosocial assessment: social functioning with special emphasis on levels of disability, needs, quality of life and social support.

Development of an individualized therapeutic plan (ITP)

- Regularly reviewed and updated (at least every three months)

- $\quad$ Modified according to patients' needs

Medical intervention:

- pharmacological treatment set up

Specific psychosocial interventions:

- Psychoeducation: educating patients and families by providing brochures and face-to-face sessions

- Family intervention: emphasis on the relationship with the patients' relatives to 
mobilize the social network (face-to-face and phone contacts)

- Support in Daily Living: education on the main aspects of personal care

- Crisis interventions and assertive outreach: being in touch with the patient or family in case of an emergency situation (community face-to-face and phone contacts)

Medical follow-up: 4-6 visits at office per year

Nursing follow-up: 12 visits at office per year

ST: Standard Treatment; CM: Case Management 
Table 2. Socio-demographic variables according to treatment programme

\begin{tabular}{|c|c|c|c|c|c|}
\hline \multirow[b]{3}{*}{ Socio-demographic variables } & \multicolumn{5}{|c|}{ Programme } \\
\hline & \multirow{2}{*}{$\begin{array}{l}\mathrm{CM} \\
\mathrm{f}(\%)\end{array}$} & \multirow{2}{*}{$\begin{array}{l}\text { ST } \\
\mathrm{f}(\%)\end{array}$} & \multicolumn{3}{|c|}{ Intergroup differences } \\
\hline & & & $\chi^{2}$ & $\mathrm{df}$ & $\mathrm{p}$ \\
\hline Male gender & $51(68.0)$ & $50(66.7)$ & 0.030 & 1 & 0.862 \\
\hline Diagnosis of schizophrenia type & & & 0.348 & 3 & 0.951 \\
\hline Paranoid & $50(66.7)$ & $50(66.7)$ & & & \\
\hline Undifferentiated & $7(9.3)$ & $8(10.7)$ & & & \\
\hline Residual & $10(13.3)$ & $8(10.7)$ & & & \\
\hline Other & $8(10.7)$ & $9(12.0)$ & & & \\
\hline Illness duration & & & 0.286 & 2 & 0.867 \\
\hline$<5$ years & $8(10.7)$ & $7(9.3)$ & & & \\
\hline From 5 to 10 years & $16(21.3)$ & $14(18.7)$ & & & \\
\hline$>10$ years & $51(68.0)$ & $54(72.0)$ & & & \\
\hline \multicolumn{6}{|l|}{ Marital status } \\
\hline Single & $59(78.7)$ & $56(74.4)$ & & & \\
\hline Married or common-law marriage & $7(9.3)$ & $11(14.7)$ & & & \\
\hline Separated, divorced or widowed & $9(12.0)$ & $8(10.7)$ & & & \\
\hline Educational level & & & 4.678 & 3 & 0.197 \\
\hline Primary school not completed & $9(12.0)$ & $7(9.3)$ & & & \\
\hline Primary school & $26(34.7)$ & $35(46.7)$ & & & \\
\hline Secondary school & $31(41.3)$ & $20(26.7)$ & & & \\
\hline College or university & $9(12.0)$ & $13(17.3)$ & & & \\
\hline Living situation & & & 5.864 & 5 & 0.320 \\
\hline Alone & $16(21.3)$ & $12(16.0)$ & & & \\
\hline
\end{tabular}


With son/daughter or son/daughter and partner

With partner

With parents

With other relatives

With other people or in an institution

Type of housing

Family-owned

Rented

Hostel, supported sheltered house, therapeutic community, homeless or others

Employment status

Employed/self-employed/supported employment/student/volunteer

House work/on sick leave/retired/unemployed

Never worked before

Incapacitated

Age

$\begin{array}{ll}5(6.7) & 7(9.3) \\ 5(6.7) & 9(12.0) \\ 35(46.7) & 39(52.0) \\ 6(8.0) & 6(8.0) \\ 8(10.7) & 2(2.7)\end{array}$

$9.832 \quad 2$

0.007

$43(57.3) \quad 60(80.0)$

$21(28.0) \quad 12(16.0)$

$11(14.7) \quad 3(4.0)$

$2.331 \quad 3$

0.507

Note. $n=75$ for the case management and the standard treatment programmes

CM: Case Management; ST: Standard Treatment; f: frequency; \%: percentage; df: degrees of freedom; SD: Standard Deviation 
Table 3. Clinical and psychosocial variables in the case management programme group and the standard treatment programme group at baseline and at one year follow-up

\begin{tabular}{|c|c|c|c|c|c|}
\hline \multirow[b]{2}{*}{ Measure } & \multirow[b]{2}{*}{ Time (months) } & \multicolumn{4}{|l|}{ Programmes } \\
\hline & & \multirow{2}{*}{$\begin{array}{l}\text { CM } \\
\text { Mean (SD) }\end{array}$} & \multirow{2}{*}{$\begin{array}{l}\text { ST } \\
\text { Mean (SD) }\end{array}$} & \multicolumn{2}{|c|}{ Intergroup differences } \\
\hline & & & & $\mathrm{t}$ & $\mathrm{p}$ \\
\hline \multirow[t]{2}{*}{ CAN patients' needs } & 0 & $9.14(7.43)$ & $7.43(3.32)$ & 2.784 & 0.006 \\
\hline & 12 & $7.89(3.56)$ & $7.01(2.80)$ & 1.527 & 0.129 \\
\hline \multirow[t]{2}{*}{ GAF clinical } & 0 & $42.03(7.15)$ & $47.01(8.71)$ & -3.834 & $<0.001$ \\
\hline & 12 & $46.65(11.20)$ & $49.14(10.46)$ & -1.351 & 0.179 \\
\hline \multirow[t]{2}{*}{ GAF social } & 0 & $40.44(8.63)$ & $45.27(9.10)$ & -3.335 & 0.001 \\
\hline & 12 & $42.35(9.43)$ & $47.04(10.77)$ & -2.725 & 0.007 \\
\hline \multirow[t]{2}{*}{ DAS-s } & 0 & $10.20(4.51)$ & $9.03(3.86)$ & 1.712 & 0.089 \\
\hline & 12 & $9.03(4.46)$ & $8.93(4.36)$ & 0.135 & 0.893 \\
\hline \multirow[t]{2}{*}{ WHOQOL-BREF physical health } & 0 & $12.64(2.25)$ & $13.61(2.29)$ & -2.614 & 0.010 \\
\hline & 12 & $13.00(2.64)$ & $13.62(2.20)$ & -1.499 & 0.136 \\
\hline \multirow[t]{2}{*}{ WHOQOL-BREF psychological health } & 0 & $11.64(2.80)$ & $12.36(2.57)$ & -1.621 & 0.107 \\
\hline & 12 & $12.02(2.82)$ & $12.46(2.56)$ & -0.969 & 0.334 \\
\hline \multirow[t]{2}{*}{ WHOQOL-BREF social relationships } & 0 & $10.17(3.20)$ & $10.52(2.90)$ & -0.713 & 0.477 \\
\hline & 12 & $12.30(3.18)$ & $10.43(2.95)$ & -0.259 & 0.796 \\
\hline \multirow[t]{2}{*}{ WHOQOL-BREF environment } & 0 & $12.75(2.28)$ & $13.16(2.04)$ & -1.156 & 0.250 \\
\hline & 12 & $13.07(2.27)$ & $13.63(2.43)$ & -1.412 & 0.160 \\
\hline \multirow[t]{2}{*}{ WHOQOL-BREF general } & 0 & $78.12(13.14)$ & $82.72(11.82)$ & -2.254 & 0.026 \\
\hline & 12 & $80.51(14.46)$ & $83.72(12.23)$ & -1.411 & 0.161 \\
\hline FSSQ total social support & 0 & $36.23(9.94)$ & $37.31(8.54)$ & -0.713 & 0.477 \\
\hline
\end{tabular}




\begin{tabular}{llllrr} 
& 12 & $37.22(10.02)$ & $36.64(8.71)$ & 0.363 & 0.717 \\
FSSQ confidant support & 0 & $16.40(5.20)$ & $16.97(4.80)$ & -0.699 & 0.486 \\
& 12 & $16.72(4.96)$ & $16.51(5.19)$ & 0.252 & 0.802 \\
FSSQ affective support & 0 & $10.82(3.20)$ & $11.16(3.08)$ & -0.652 & 0.516 \\
& 12 & $11.16(3.18)$ & $10.75(3.11)$ & 0.757 & 0.450 \\
\hline
\end{tabular}

Note. $\mathrm{n}=75$ at baseline and $\mathrm{n}=69$ at one year follow-up for the case management and standard treatment programmes

CM: Case Management; ST: Standard Treatment; SD: Standard Deviation; CAN: Camberwell Assessment of Needs Questionnaire; PANSS: Positive and Negative Syndrome Scale; GAF: Global Assessment of Functioning; DAS-s: Disability Assessment Schedule Short Form; WHOQOL-BREF: World Health Organization Quality of Life Scale Brief Version; FSSQ: Modified DUKE-UNC Functional Social Support Questionnaire 
Table 4. Use of services (categorical variables) according to treatment programme

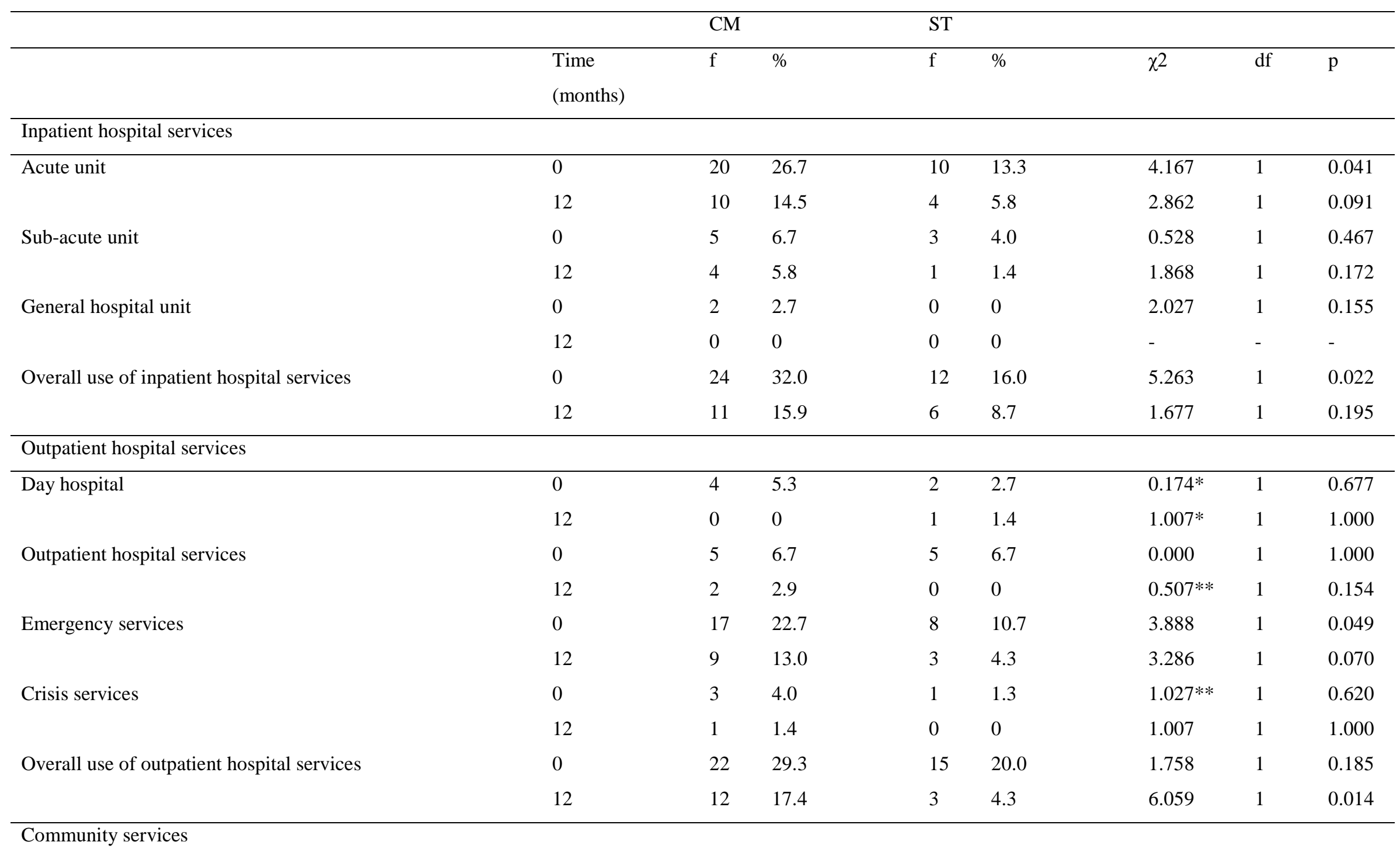




\begin{tabular}{|c|c|c|c|c|c|c|c|c|}
\hline \multirow[t]{2}{*}{ Community psychological services } & 0 & 10 & 13.3 & 10 & 13.3 & 0.000 & 1 & 1.000 \\
\hline & 12 & 6 & 8.7 & 6 & 8.7 & 0.000 & 1 & 1.000 \\
\hline \multirow[t]{2}{*}{ Community social work services } & 0 & 42 & 56 & 33 & 44.0 & 2.160 & 1 & 0.142 \\
\hline & 12 & 52 & 69.3 & 38 & 50.7 & 5.444 & 1 & 0.020 \\
\hline \multirow[t]{2}{*}{ Community rehabilitation services } & 0 & 16 & 21.3 & 13 & 17.3 & 0.385 & 1 & 0.535 \\
\hline & 12 & 19 & 27.5 & 12 & 17.4 & 2.039 & 1 & 0.153 \\
\hline \multirow[t]{2}{*}{ Specialised rehabilitation services } & 0 & 14 & 18.7 & 8 & 10.7 & 1.918 & 1 & 0.166 \\
\hline & 12 & 16 & 23.2 & 9 & 13.0 & 2.394 & 1 & 0.122 \\
\hline \multirow[t]{2}{*}{ Protected vocational workshops } & 0 & 6 & 8.0 & 6 & 8.0 & 0.000 & 1 & 1.000 \\
\hline & 12 & 3 & 4.3 & 6 & 8.7 & 1.070 & 1 & 0.301 \\
\hline \multirow[t]{2}{*}{ Educational, vocational or leisure services } & 0 & 11 & 14.7 & 18 & 24.0 & 2.095 & 1 & 0.148 \\
\hline & 12 & 10 & 14.5 & 15 & 21.7 & 1.221 & 1 & 0.269 \\
\hline \multirow[t]{2}{*}{ Social services } & 0 & 16 & 21.3 & 1 & 1.3 & 14.927 & 1 & 0.000 \\
\hline & 12 & 9 & 13.0 & 2 & 2.9 & 4.840 & 1 & 0.028 \\
\hline \multirow[t]{2}{*}{ Emergency phone calls } & 0 & 9 & 12.0 & 6 & 8.0 & 0.667 & 1 & 0.414 \\
\hline & 12 & 4 & 5.8 & 5 & 7.2 & 0.119 & 1 & 0.730 \\
\hline \multicolumn{9}{|l|}{ Primary care services } \\
\hline \multirow[t]{2}{*}{ General practitioner } & 0 & 47 & 62.7 & 47 & 62.7 & 0.000 & 1 & 1.000 \\
\hline & 12 & 49 & 71.0 & 52 & 75.4 & 0.332 & 1 & 0.564 \\
\hline \multirow[t]{2}{*}{ Primary care nursing } & 0 & 19 & 25.3 & 25 & 33.3 & 1.158 & 1 & 0.282 \\
\hline & 12 & 17 & 24.6 & 28 & 40.60 & 3.990 & 1 & 0.046 \\
\hline \multirow[t]{2}{*}{ Home, family and social work } & 0 & 9 & 12.0 & 3 & 4.0 & 3.261 & 1 & 0.071 \\
\hline & 12 & 7 & 10.1 & 5 & 7.2 & 0.356 & 1 & 0.546 \\
\hline
\end{tabular}

CM: Case Management; ST: Standard Treatment; f: frequency; \%: percentage; df: degrees of freedom 
Table 5. Service use variables in the case management programme group and the standard treatment programme group at baseline and at one year follow-up

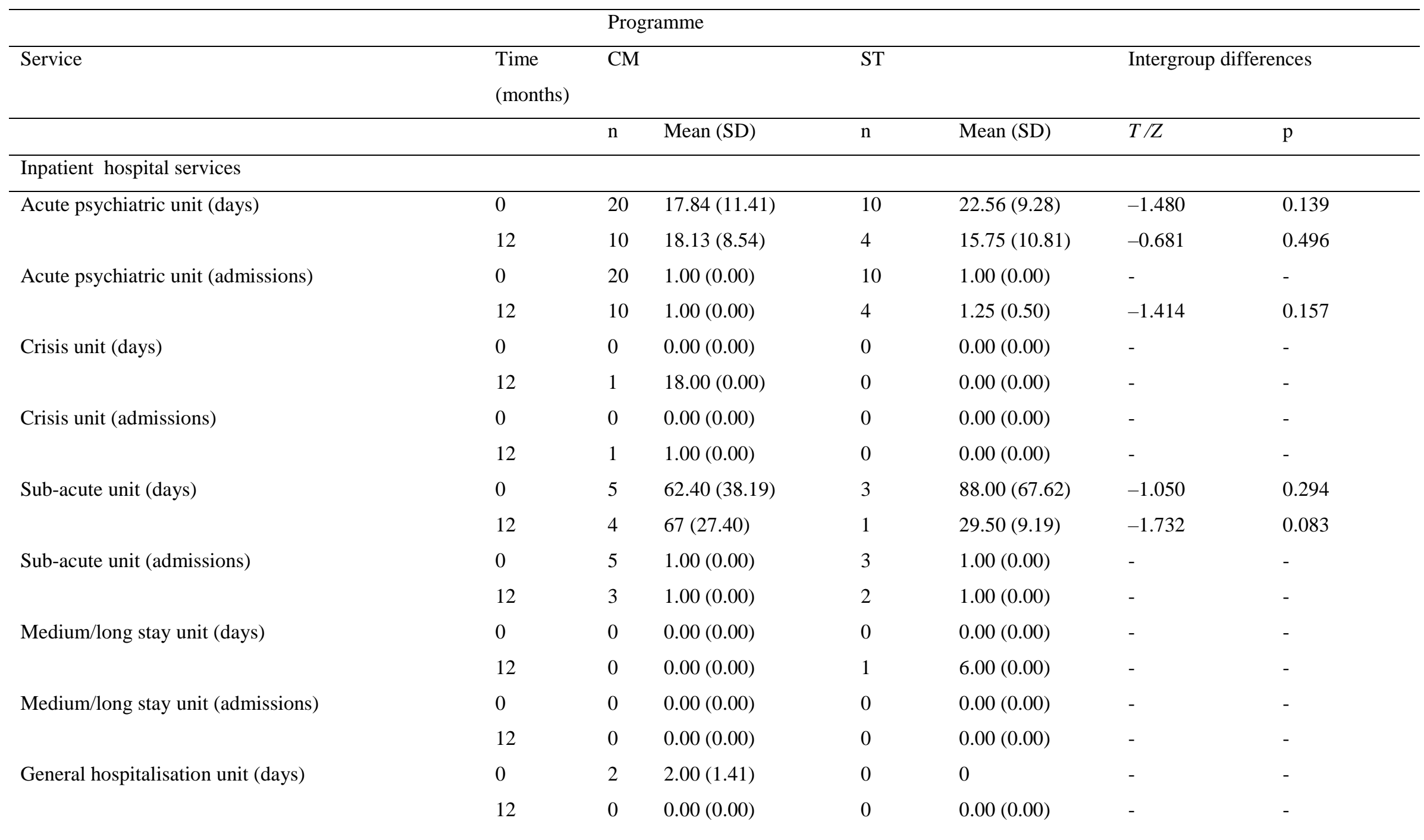




\begin{tabular}{|c|c|c|c|c|c|c|c|}
\hline \multirow[t]{2}{*}{ General hospitalisation unit (admissions) } & 0 & 2 & $1.00(0.00)$ & 0 & 0 & - & - \\
\hline & 12 & 0 & $0.00(0.00)$ & 0 & $0.00(0.00)$ & - & - \\
\hline \multirow[t]{2}{*}{ Overall inpatient hospital (days) } & 0 & 24 & $29.68(29.86)$ & 12 & $21.30(9.60)$ & -0.293 & 0.770 \\
\hline & 12 & 11 & $46.18(51.20)$ & 6 & $21.33(19.49)$ & -1.409 & 0.159 \\
\hline \multirow[t]{2}{*}{ Overall inpatient hospital (admissions) } & 0 & 24 & $1.00(0.00)$ & 12 & $1.00(0.00)$ & - & - \\
\hline & 12 & 11 & $1.45(0.69)$ & 6 & $1.00(0.00)$ & -1.348 & 0.178 \\
\hline \multicolumn{8}{|l|}{ Outpatient psychiatric hospital services } \\
\hline \multirow[t]{2}{*}{ Outpatient hospital visits } & 0 & 5 & $17.80(13.18)$ & 5 & $1.25(0.50)$ & -2.491 & 0.013 \\
\hline & 12 & 2 & $3.00(2.83)$ & 0 & 0 & - & - \\
\hline \multirow[t]{2}{*}{ Crisis unit visits } & 0 & 3 & $1.00(0.00)$ & 1 & $4.00(0)$ & -1.732 & 0.083 \\
\hline & 12 & 1 & $1.00(0.00)$ & 0 & 0 & - & - \\
\hline \multirow[t]{2}{*}{ Emergency service visits } & 0 & 17 & $1.53(0.74)$ & 8 & $1.38(0.74)$ & -0.612 & 0.540 \\
\hline & 12 & 9 & $2.11(1.69)$ & 3 & $16.67(24.58)$ & -1.025 & 0.413 \\
\hline \multirow[t]{2}{*}{ Day hospital } & 0 & 4 & $55.00(54.08)$ & 2 & $160.00(224.86)$ & -0.651 & 0.628 \\
\hline & 12 & 0 & $0.00(0.00)$ & 1 & $9.00(0.00)$ & - & - \\
\hline \multirow[t]{2}{*}{ Outpatient psychiatric hospital visits } & 0 & 20 & $8.40(11.24)$ & 13 & $1.62(0.96)$ & 2.684 & 0.039 \\
\hline & 12 & 12 & $2.17(1.75)$ & 3 & $19.67(29.77)$ & -1.023 & 0.306 \\
\hline \multicolumn{8}{|l|}{ Community services } \\
\hline \multirow[t]{2}{*}{ Community psychiatric visits } & 0 & 73 & $5.85(2.94)$ & 73 & $4.70(2.54)$ & 2.528 & 0.013 \\
\hline & 12 & 68 & $6.18(3.50)$ & 69 & $5.22(2.57)$ & 1.830 & 0.069 \\
\hline \multirow[t]{2}{*}{ Community psychology visits } & 0 & 10 & $4.22(2.86)$ & 10 & $5.90(4.41)$ & -0.495 & 0.621 \\
\hline & 12 & 6 & $6.50(4.51)$ & 6 & $4.67(2.94)$ & -1.158 & 0.247 \\
\hline \multirow[t]{2}{*}{ Community psychiatric nursing visits } & 0 & 75 & $7.81(7.48)$ & 74 & $4.42(5.38)$ & 3.183 & 0.002 \\
\hline & 12 & 69 & $11.64(8.35)$ & 68 & $4.94(5.97)$ & 5.409 & 0.000 \\
\hline \multirow[t]{2}{*}{ Community social work visits } & 0 & 42 & $4.55(3.59)$ & 33 & $4.79(3.57)$ & -0.288 & 0.774 \\
\hline & 12 & 52 & $3.82(3.21)$ & 38 & $4.09(2.61)$ & -0.394 & 0.695 \\
\hline
\end{tabular}


